\title{
Análise do Processo Produtivo de Filmes Poliméricos Utilizando a Metodologia de Produção Mais Limpa
}

Analysis of the production process of polymer films using the methodology of cleaner production

\author{
Aline Aumiller', Camilla Esteban Oliveira², Jane Maria Faulstich Paiva ${ }^{3}$, \\ Juliana Veiga Mendes ${ }^{4}$, Virgínia Aparecida Silva Moris
}

\begin{abstract}
' Ex-Aluna do curso de Engenharia de Produção, Departamento de Engenharia de Produção, Universidade Federal de São Carlos, Sorocaba, Brasil
${ }^{2}$ Aluna do curso de Engenharia de Produção, Departamento de Engenharia de Produção, Universidade Federal de São Carlos, Sorocaba, Brasil.

${ }^{3}$ Professora do Curso de Graduação de Engenharia de Produção e Pós Graduação em Ciências dos Materiais, Universidade Federal de São Carlos, Sorocaba, Brasil.

4, 5 Professora do Curso de Graduação e Pós Graduação de Engenharia de Produção, Departamento de Engenharia de Produção, Universidade Federal de São Carlos, Sorocaba, Brasil
\end{abstract}

\begin{abstract}
Resumo
GO avanço tecnológico norteia ações que contribuem para o estudo e implantação de um sistema de gestão ambiental estruturado dentro das empresas. Dentro deste contexto, este trabalho aborda o estudo da aplicação da metodologia da Produção Mais Limpa (PML) em uma empresa de embalagens de filmes poliméricos flexíveis de BOPP (Polipropileno Biorientado) na região de Sorocaba, que almejou identificar oportunidades de melhorias que podem impactar na redução de impactos ambientais. As visitas técnicas realizadas na empresa auxiliaram no mapeamento e entendimento do processo produtivo. O uso da metodologia de PML permitiu a identificação de possíveis melhorias no processo visando minimização de geração de resíduos, matéria-prima, água e energia. No caso foi utilizado um modelo de transformação para realizar o mapeamento do processo produtivo. As oportunidades de futuras melhorias foram identificadas e enquadradas nos níveis estratégicos da PML, algumas delas estão relacionadas às melhorias na utilização de matérias-primas, redução de vazamento de água para o processo nas tubulações, alteração de matéria-prima de fonte não renovável para renovável, realização de manutenção preventiva, minimização da geração de resíduos, utilização do material regranulado gerado no processo etc. Para futuros trabalhos devem ser realizadas as viabilidades econômica e técnica de cada proposta identificada no presente trabalho.
\end{abstract}

Palavras-chave: Produção Mais Limpa; Filme Polimérico; BOPP; Desenvolvimento Sustentável.

\begin{abstract}
The current technological advance guides the actions that have contributed to the study and implementation of a structured environmental management within companies. Thereby, this article discusses the application of Cleaner Production Methodology in a company engaged in the business of flexible films in the region of Sorocaba, São Paulo, Brazil. The study aims to identify opportunities of improvements that might reduce the environmental impact. There were visits in the enterprise during the execution of the project in order to get quantitative and qualitative data, which supported the mapping and understanding of the productive process. The application of Cleaner Production has allowed the identification of improvements in the process, better use of raw material, reduction of water use and minimization of waste generation. In this case, it has been used an adapted transformation model to map the system. Opportunities for future improvements have been identified and classified into the strategic levels of the Cleaner Production; some of them are related to the progress in the use of raw materials, reduction of water leaks through the process in the pipes, change of raw material from nonrenewable to renewable source, performance of preventive maintenance, minimization of waste generation, use of regranulated material generated in the process, etc. Therefore, for futures studies, it may be accomplished the analysis of economic and technical feasibility of each proposal identified in this report
\end{abstract}

Keywords: Cleaner Production; BOPP Film; Sustainable Development. 


\section{INTRODUÇÃO}

A minimização dos efeitos negativos gerados para o ambiente e para a sociedade tornou-se um tema decorrente nos dias atuais, por sua vez, as empresas procuram uma forma de agregar valor aos seus produtos minimizando desperdícios e utilizando novas e mais eficientes tecnologias. Além disso, o acirramento da competição mundial e a globalização da economia elevam a escala produtiva, com a consequente busca da minimização da geração de resíduos, consumo de matéria-prima, água e energia, redução dos custos, melhoria de processos e desenvolvimento de novos produtos (CETESB, 2002).

A Lei número 12.305/10, que decreta a Política Nacional de Resíduos Sólidos (PNRS), permite mitigar os impactos econômicos, sociais e ambientais do manejo inadequado dos resíduos sólidos. A PNRS visa estabelecer metas de redução de geração de resíduos, aumentar o volume de reciclagem e possibilitar o destino correto dos rejeitos (resíduos que não podem ser reaproveitados). A Lei institui a responsabilidade compartilhada, quanto aos geradores de resíduos: indústrias, importadores, distribuidores, comerciantes e consumidores. Todos devem, positivamente, colaborar com a gestão dos resíduos sólidos (MMA, 2013).

Adicionalmente, a legislação ambiental prevê, além da criação e execução de programas ou projetos de educação ambiental para os trabalhadores, por meio da Política Nacional de Educação Ambiental (Lei n 9.795/99), a implementação de programas de controle da poluição cujas diretrizes se encontram na PRNS.

Diante deste panorama as empresas passam a se reestruturar para se adequarem a esta nova percepção buscando alternativas inovadoras que reduzam o impacto ambiental. Tais mudanças estão sendo incentivadas devido as novas legislações, pressões sociais, do governo e dos consumidores. A fim de melhorar sua imagem frente a sua responsabilidade social, muito tem sido feito para se alcançar o desenvolvimento sustentável no setor produtivo (CORAL, 2002).

Como estratégia aplicada à Gestão Ambiental, a Produção Mais Limpa (PML) é indicada como uma ferramenta que possibilita o funcionamento da empresa de modo social e ambientalmente responsável, ocasionando também influência em melhorias econômicas e tecnológicas. A PML aplica uma abordagem preventiva na Gestão Ambiental. (SILVA FILHO e SICSÚ;2003).

Compatível com uma visão abrangente, a PML é um conceito internacionalmente reconhecido como uma abordagem moderna e eficaz de se analisar e gerenciar os recursos de produção, dentro de uma visão preventiva e proativa quanto à geração de resíduos e desperdícios (CNTL, 2003).

Lopes Silva et al. (2012) reforçam que os programas de PML representam uma estratégia "ganha-ganha", na qual a otimização do uso de recursos leva à redução de custos e maior rentabilidade implicando na redução de impactos ambientais.

As embalagens tornaram-se uma preocupação recorrente, desde a década de 80, até os dias atuais. Por exemplo, as indústrias de embalagens de alimentos vêm atrelando a busca do desenvolvimento sustentável nos processos produtivos devido a importância das embalagens no cotidiano pois protegem e agregam valor ao produto, porém não são os focos do consumo e apresentam impactos ambientais desde a sua produção até o descarte. Atualmente, dentre os impactos ambientais consequentes pelo cotidiano da vida contemporânea, àqueles causados pelas embalagens é um dos mais sérios e preocupantes (LECETA et. al., 2013).

Os materiais utilizados nas embalagens contribuem para intensificação de problemas ambientais pelo consumo de recursos e energia utilizados na produção das embalagens e fluxo de resíduos resultantes e sua gestão no final da utilização da embalagem (descarte). Atualmente, a atenção da sociedade consciente e dos pesquisadores técnicos e científicos está voltada a minimizar os impactos ambientais associados à aquisição e produção das embalagens e também à recuperação de recursos no final de sua vida útil (WILLIAMS e WIKSTRÖM (2011)).

O filme de polipropileno biorientado (BOPP) é uma embalagem muito utilizada para fabricação de fitas adesivas, embalagens e rótulos na indústria alimentícia e de cosméticos, pois apresenta ótimas características mecânicas (rigidez, alta resistência, barreira a gases, estabilidade dimensional, resistência a várias temperaturas) e também estéticas, como brilho e transparência. Devido a sua grande escala de produção e aplicação torna-se relevante e de valor social, econômico e ambiental que os processos produtivos de BOPP estejam acordados às normas favoráveis ao meio ambiente.

Quando é empregado na embalagem final do produto, o filme de BOPP pode ser combinado com outros plásticos, ou com lâminas de alumínio para aumentar a sua resistência mecânica e a per- 
meabilidade a gases (CARVALHO, 2008). De acordo com Siderurgia Brasil (2010), a combinação do alumínio em filme de BOPP mostra que a espessura da camada de alumínio presente na embalagem do polipropileno biorientado metalizado é cerca de 1.000 vezes menor que a espessura do filme de BOPP, o que facilita o processo de reciclagem. Assim, essas embalagens possuem o símbolo de reciclável e podem ser coletadas juntamente com os plásticos.

Cerca de 40 milhões de toneladas de polipropileno biorientado (BOPP) são atualmente produzidas por ano no mundo. O filme de BOPP é responsável pelo uso de grande quantidade do polipropileno, uma vez que é adequado para as películas de embalagem de alimentos ou de folhas industriais (fitas adesivas, etiquetas, plastificação, entre outros), devido ao seu elevado desempenho em termos de propriedades mecânicas e ópticas (TAMURA, OHTA, KANAI, 2012).

O Brasil é responsável por $60 \%$ do consumo sul-americano de embalagens flexíveis e a empresa produtora de BOPP, que desenvolveu um papel sintético feito a partir de plásticos reciclados, detém $52 \%$ do mercado nacional, sendo que $64 \%$ da produção são destinados aos segmentos de embalagens (SIDERURGIA BRASIL, 2010).

Analisar o processo produtivo de um produto importante na economia com ferramentas de gestão ambiental, como, por exemplo, a PML e análise de ciclo de vida (ACV), podem trazer resultados de minimização de impactos ambientais e maximização de produção em escalas consideráveis, impactando positivamente a sociedade e servindo de exemplo para demais empresas e produtos difundidos no mercado se preocuparem em atingir metas ambientalmente corretas. (CARVALHO, 2008).

Considerando a PML como uma metodologia que suporta as ações da empresa em relação a Gestão Ambiental e compreendendo que pode auxiliar a análise dos processos e, com isso, a identificação de potenciais de melhoria, esse estudo tem como objetivo apresentar os resultados obtidos com a aplicação da metodologia PML, em uma indústria do ramo de embalagens flexíveis, como ferramenta para análise e melhoria de processos visando contemplar os aspectos ambientais.

\section{I.I Produção MaIs Limpa}

$\mathrm{O}$ foco da metodologia de PML se encontra em melhorar a eficiência, a lucratividade e a competitividade das empresas através da diminuição da geração de resíduos, tornando os processos mais eficientes e menos poluidores. O principal desafio das empresas é colocar entre seus planos estratégicos a PML que, comprovadamente, agrega benefícios ambientais, econômicos e de saúde ocupacional. Para isso, a metodologia propõe que as empresas invistam em tecnologias que auxiliem a redução de resíduos, definindo uma série de etapas que servem como guias aos gestores para a implementação da metodologia (HINZ, 2006).

A prevenção da geração é importante, pois, além de visar à otimização do processo, devido a utilização da menor quantidade possível de matéria-prima e insumos, objetiva garantir a redução da geração dos resíduos (resíduo sólido, efluente líquido ou emissão atmosférica), evitando, portanto, a necessidade de implementação de ações para seu manuseio, estocagem, transporte, tratamento e disposição final, a qual, muitas vezes, é feita em aterros sanitários ou industriais, de forma menos qualificada possível (CEBDS, 2012).

Podem ser utilizadas várias estratégias visando a PML que podem ser subdividas em níveis, conforme apresentado na Figura 1. A PML se enquadra como uma aplicação contínua de uma estratégia técnica, econômica e ambiental, com foco em produtos e processos.

O nível 1 de PML inclui ações mais complexas objetivando minimizar as emissões sólidas, líquidas e gasosas do processo produtivo na fonte. Este nível compreende ações que vão desde modificações no produto até alterações do processo. Para tanto, podem ser utilizadas técnicas de boas práticas de fabricação, substituição de matérias-primas e modificações tecnológicas. (CNTL, 2003).

Abaixo são listadas algumas alternativas referentes a modificações no processos:

- Técnicas de housekeeping: consiste em limpezas periódicas, uso cuidadoso de matérias-primas (MP) e com o processo, alterações no layout, elaboração de manuseio para materiais e recipientes, etc. Permite também mudanças nas condições operacionais: alterações nas vazões, temperaturas, pressões, tempos de residência e outros fatores que atendam às práticas de prevenção de resíduos;

- Substituição de MP: consiste na identificação de materiais mais resistentes que possam vir a reduzir perdas por manuseio operacional, substituição de materiais tóxicos por atóxicos e não-renováveis por renováveis;

- Mudanças tecnológicas: equipamentos mais eficientes do ponto de vista da otimização dos 
recursos utilizados, uso de controles e de automação que permitam identificar perdas ou reduzir o risco de acidentes de trabalho, etc.

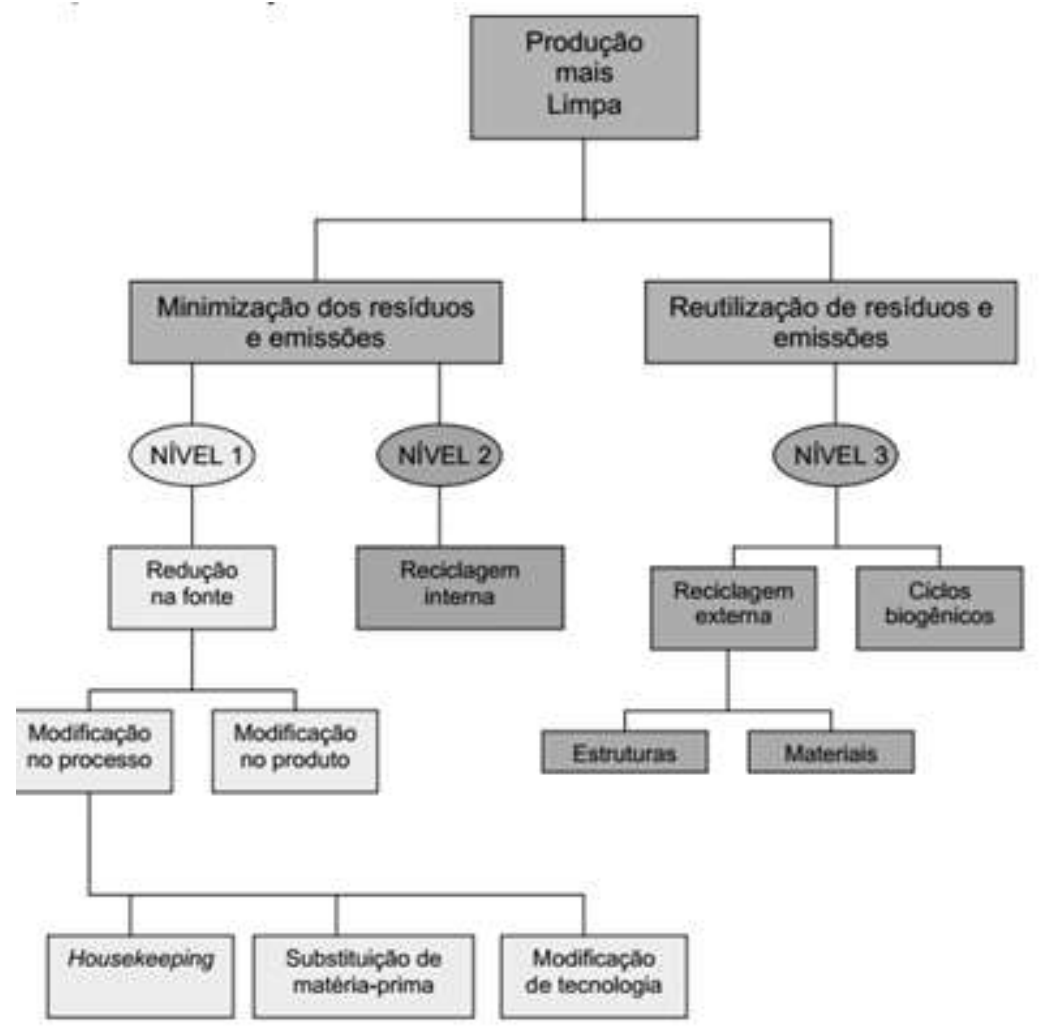

Figura 1. Níveis da Produção Mais Limpa (CNTL, 2003).

E referente a modificações no produto:

- Substituição de produto: pode envolver o cancelamento de uma linha produtiva, no qual o produto acabado apresente problemas ambientais significativos, ou ainda, a substituição de um produto com características tóxicas por outro menos tóxico;

- Redesenho do produto (ecodesign): desenvolver uma nova concepção do produto que leve em consideração a variável ambiental como fator de redução de custos e oportunidades de negócios. Atualmente muito tem sido desenvolvido com o foco do design pensando na desmontagem, tanto para remanufatura, reciclagem, reuso, etc. O design para remanufatura aumenta a eficiência considerando uma série de atividades nas quais as prioridades irão ser dependentes das necessidades do produto (HATCHER; IJOMAH; WINDMILL, 2011). Isso pode facilitar, por exemplo, a desmontagem dos produtos.

Nesta fase, há necessidade de uma análise combinada de substituição de materiais tóxicos por atóxicos e não renováveis por renováveis, alterações nas dimensões do produto, aumento da vida útil do produto, facilidade de reciclagem de seus componentes e otimização produtiva ou de processos.

O nível 2 objetiva a minimização de resíduos através da reciclagem interna, ou seja, todo resíduo oriundo do processo produtivo é reprocessado internamente (CNTL, 2003). E o nível 3 apresenta a oportunidade de reuso dos resíduos através da reciclagem externa. Neste nível, os materiais são comercializados para terceiros que os reciclarão ou os utilizarão como matérias-primas para novos produtos. (CNTL, 2003).

Sintetizando, a prioridade da PML é minimizar a geração de resíduos e emissões (nível 1). Os resíduos que não puderem ser evitados devem, preferencialmente, ser reintegrados ao processo de produção da empresa (nível 2). Na sua impossibilidade, medidas de reciclagem fora da empresa (reciclagem externa) devem ser utilizadas (nível 3). Esses três níveis de PML norteiam as empresas que objetivam reutilizar ou minimizar a geração de resíduos sólidos e emissões em seus processos (CNTL, 2003).

De acordo com Fresner (2004), estudos realizados analisando experiências de gestão ambien- 
tal em empresas de menor porte têm evidenciado que o ponto central de qualquer metodologia para implantação da PML consiste em identificar boas opções para aumentar a eficiência no uso de materiais, água e energia.

Faria (2011) utilizou a PML na identificação de mudanças operacionais na reciclagem mecânica de plástico em sete recicladoras de plástico, principalmente de polietileno (PE), a fim de torná-lo adequado, sob o ponto de vista ambiental. Foi aplicado um questionário, visando obter informações referentes à produção, ao consumo de utilidades, à formação de resíduos e emissões. As etapas do processo de reciclagem analisadas foram separação, moagem, lavagem, secagem e processamento. $\mathrm{O}$ estudo apontou que as principais deficiências do processo estão no excessivo consumo de energia, a não reutilização da água de processo e a geração de resíduos. Foram identificadas algumas possíveis melhorias nos processos de reciclagem estudados: manutenção periódica dos acessórios do moinho e a captação dos materiais particulados; na etapa de lavagem, com o tratamento da água residual; na extrusão do material plástico, com a reutilização da água de resfriamento e a otimização das condições de processamento.

Correia e Jerônimo (2012) utilizaram a metodologia de PML seguindo a seguinte priorização para identificação de oportunidades: eliminação na fonte, minimização do consumo; reciclagem ou reaproveitamento interno ou externo, tratamento e disposição final. Os resultados apontam para projetos associados a redução de vazamentos em sistemas de bombeamento de água captada para formulação de fluidos; redução dos vazamentos de vapor; utilização de água salobra/salina proveniente de poços de captação mais profundos em substituição à água doce de poços de captação; utilização/Reuso (externo) de água de esgotos em substituição à água doce captada e usada para injeção; uso de água oceânica (captada do mar) em substituição à água doce captada , para fins de recuperação secundária; adoção de equipamento/sistema de elevação de petróleo com recursos de DOWS - Downhole Oil Water Separation (Separação óleo/água no fundo do poço) e uma maior automação. Foram identificadas oportunidades que impõe a necessidade de elevados níveis de investimentos financeiros, porém, que tendem a gerar resultados econômicos significativos. Logo, sugere-se que estudos complementares sejam realizados para mensurar os ganhos econômicos das oportunidades identificadas.

Zampollo e Neder (2013) descrevem as iniciativas, vantagens e barreiras que a Petrobrás vem trabalhando, desde 2011, na implementação de projetos baseados na metodologia de PML, no âmbito de um programa corporativo. Foram identificadas propostas de melhorias relacionadas à minimização da geração de resíduos e efluentes, deixando clara a possibilidade de se estudar e tratar um universo vasto de situações. Em todos os processos estudados o resultado identificou um resíduo gerado em maior quantidade, por exemplo: tambores e bombonas contaminados, resíduos recicláveis, água usada, lixo comum, embalagens de produtos químicos, embalagens recicláveis, efluentes líquidos, restos de produtos químicos, embalagens do tipo cartonada (Tetrapack), etc. Uma proposta que ficou para avaliação foi a viabilidade de redução do uso de água doce industrial, utilizada em plataforma marítima, considerando sua substituição por água do mar, por meio da aquisiçãode um equipamento de dessalinização. A situação atual de implementação e as ações futuras a serem desenvolvidas estão sendo monitoradas de forma corporativa e serão objeto de um relatório específico sobre a metodologia de PML na companhia.

\section{I.2 PROCESSO PRODUtiVo do BOPP}

O filme de BOPP (polipropileno biorientado) pode ser obtido diretamente da industrialização do polímero de polipropileno através de processo de extrusão e estiramento. Tais filmes se diferem dos filmes de polipropileno convencionais por serem submetidos no processo por um estiramento tanto no sentido longitudinal quanto no sentido transversal à extrusão (CARVALHO, 2008).

O filme de BOPP é constituído basicamente por duas capas exteriores compostas por polímeros, copolímeros, aditivos e por uma camada interna formada por homopolímeros e material reciclado. Os aditivos possuem a finalidade de conferir ao material as propriedades desejadas de acordo com a aplicação e especificação do cliente (CARVALHO, 2008).

Os filmes BOOP mais comuns são os transparentes, mas também existem no mercado filmes BOPP brancos, perolados e mates (estes últimos com um crescimento significativo de utilização); e em menor quantidade os pigmentados de várias cores. Apresenta-se em filmes e películas para embalagens de diferentes aplicações principalmente na indústria alimentícia. Quando empregado na embalagem final do produto, o BOPP pode ser combinado com outros plásticos, ou com lâminas de alumínio para 
aumentar a resistência mecânica e a permeabilidade a gases (CARVALHO, 2008).

$\mathrm{O}$ processo de BOPP, estudado produz filmes biaxialmente orientados em um processo de dois estágios, o que significa que o filme é submetido a estiramento em duas direções ortogonais em um mesmo plano, na direção da máquina, e na direção transversal. O processo de produção tem início com a alimentação das matérias-primas através de um sistema de transporte pneumático para os silos intermediários que alimentam a área de extrusão composta pela extrusora principal e coextrusoras. Em seguida, as matérias-primas passam por uma unidade de dosagem, dependendo da demanda do cliente, o material segue então para o misturador onde é homogeneizado, garantindo uma alimentação da extrusora com material de densidade uniforme. A Figura 2 ilustra uma linha de produção das bobinas de BOPP (MIGUEL, 2003).

Nesta fase do processo obtém-se uma placa de polipropileno que é resfriada ao entrar em contato com um rolo cromado denominado "chill roll" que é refrigerado internamente por água gelada circulando através de uma serpentina e externamente mergulhado em um banho de água gelada.

Em seguida, o filme é conduzido para a unidade de estiramento longitudinal, MDO (Machine Direction Orienter), que tem por finalidade estirar o filme na direção longitudinal.

O T.D.O.(Transverse Orienting Machine) é o equipamento que realiza a orientação do filme na direção transversal. Neste equipamento se processa o estiramento transversal no filme proveniente do MDO que já está estirado e orientado longitudinalmente. O filme é transportado através do T.D.O. por grampos montados sobre uma corrente transportadora. Nesta mesma etapa ocorre o corte das orelas, que são as margens do filme danificadas pelos grampos.

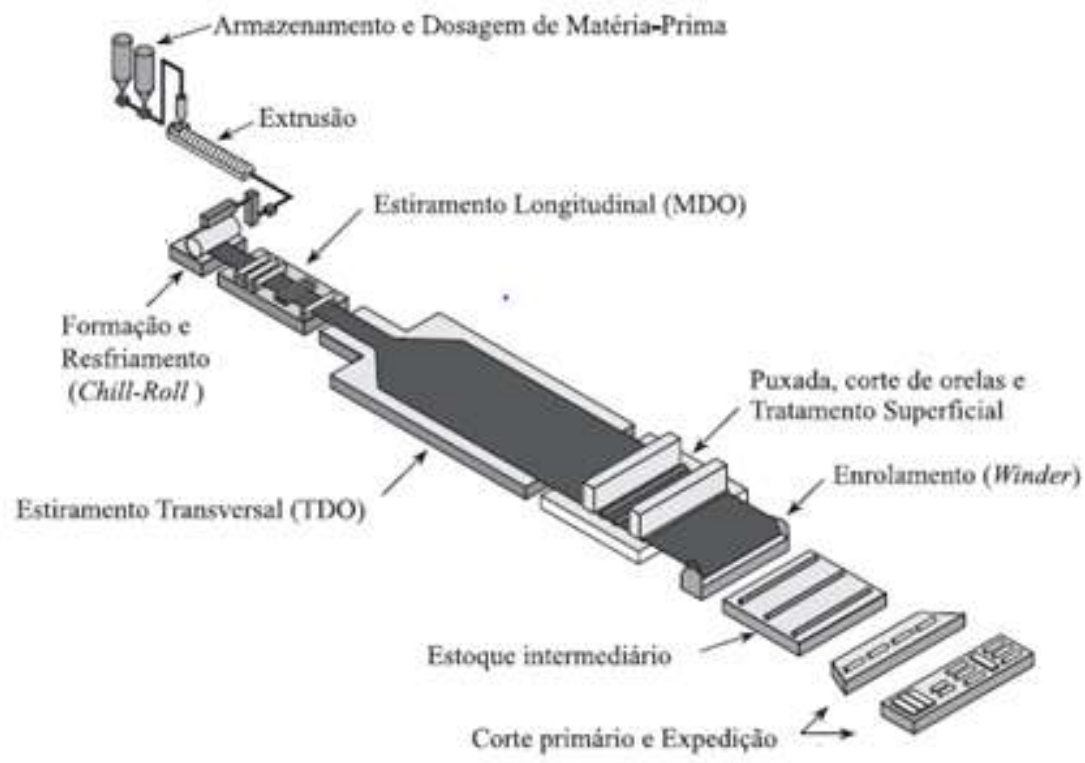

Figura 2. Processo de Fabricação de Filme de BOPP (MIGUEL, 2003).

Na etapa seguinte, pull-roll, o filme pode receber diferentes tratamentos superficiais (por exemplo, descarga corona), que variam de acordo com sua aplicação. Após o pull-roll existe a unidade denominada Winder que tem a finalidade de bobinar de forma contínua e ininterrupta o filme produzido formando as chamadas bobinas jumbo que são enviadas ao Corte, conforme as especificações de cada cliente.

$\mathrm{Na}$ sequência, uma parte dos filmes segue para o processo de metalização, onde recebe uma camada adicional de alumínio, proveniente da evaporação de fios de alumínio. Os filmes Metalizados e Não Metalizados seguem para o estoque e expedição. Todos os cortes de bordas, restos ou filmes fora de especificação são enviados para reciclagem e são submetidos a um processo de trituração resultando em um material granulado (denominado regranulado, na indústria), onde parte deste material é reincorporado ao processo de fabricação do filme (reciclagem interna) ou segue para reciclagem externa. 


\section{METODOLOGIA}

O método de pesquisa utilizado foi o estudo de caso que, segundo VOSS et al. (2002), é a história de um fenômeno passado ou corrente, delineado por múltiplas fontes de evidências. No presente estudo foi analisado um fenômeno atual, que é busca pela redução de impactos ambientais causados pelo processo produtivo analisado utilizando uma ferramenta de gestão ambiental, a PML.

A empresa estudada atua no setor de embalagens, rótulos/etiquetas e industrial gráfico, com capacidade produtiva de aproximadamente 127 mil toneladas de filmes flexíveis (BOPP) ao ano. Estes filmes flexíveis são fabricados por um processo de estiramento que aumenta as propriedades mecânicas e brilho enquanto diminui a elasticidade, opacidade e permeabilidade a gases e vapores do material oferecendo, por exemplo, no caso de embalagens de alimentos, maior durabilidade de conservação, medido pelas empresas como tempo de prateleira (shelf life).

Foram necessárias visitas técnicas na empresa para a coleta de dados e mapeamento do processo produtivo, alinhamento de objetivos e integração com os colaboradores da empresa em questão. O setor de manufatura foi priorizado por suas características típicas, que tem como output o produto final (BOPP) e a liberação de resíduos provenientes de materiais utilizados pelo processo de transformação.

A aplicação da metodologia de PML foi baseada em algumas etapas propostas pelo SEBRAE (SEBRAE,2005). As etapas são apresentadas a seguir:

1- Comprometimento da empresa: Apresentação da metodologia e sensibilização dos funcionários

2- Identificação de barreiras

3- Pré-avaliação e diagnóstico

4- Listar entradas e saídas do processo produtivo

5- Elaborar fluxogramas

6- Coleta e preenchimento de dados quantitativos e qualitativos

7- Seleção do foco de avaliação

8- Avaliação das causas

9- Oportunidades de PML

No caso, o mapeamento dos processos produtivos foi uma atividade contemplada, principalmente, nas etapas 4, 5, 6 e 7 listadas acima. Ele foi conduzido considerando o modelo de transformação, proposto por Slack (2009), que segundo o autor, permite mapear os processos produtivos que transformam recursos de entrada (inputs) em saídas (outputs). A representação gráfica do modelo apresentada pelo autor é simples como ilustra a figura 3 .

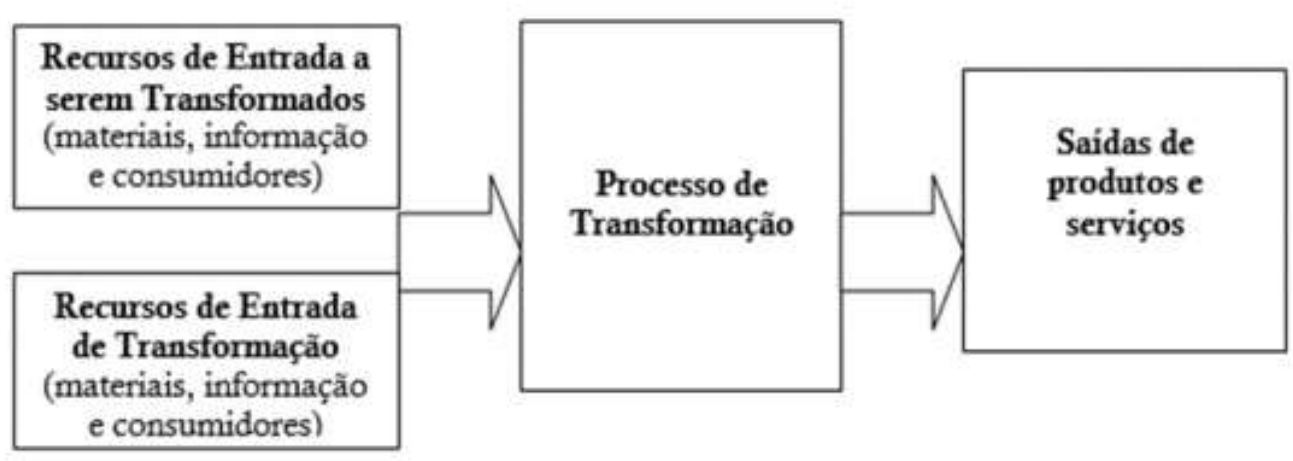

Figura 3 - Modelo de transformação (SLACK, 2009)

\section{RESULTADOS E DISCUSSÕES}

A revisão bibliográfica e a aplicação das etapas de PML, incluindo o mapeamento do processo, suportaram a identificação de oportunidades de melhoria no processo estudado. As Tabelas 1 e 2 apresentam as etapas propostas pelo SEBRAE (2005) realizadas no presente estudo e as barreiras que foram identificadas. 
Tabela 1 - Atividades realizadas na aplicação da metodologia proposta por SEBRAE (2005).

\begin{tabular}{|c|c|c|}
\hline & Etapa & Aplicação \\
\hline 1 & $\begin{array}{l}\text { Comprometiment } \\
\text { o da empresa }\end{array}$ & $\begin{array}{l}\text { Levantamento da documentação de trabalhos } \\
\text { realizados anteriormente alinhados ao foco de } \\
\text { impactos ambientais; } \\
\text { Apresentação da metodologia de PML em reunião } \\
\text { com a alta gerência e demais envolvidos no projeto; } \\
\text { Apresentação do estudo a ser conduzido aos } \\
\text { funcionários de diferentes áreas da empresa. }\end{array}$ \\
\hline 2 & $\begin{array}{l}\text { Identificação de } \\
\text { barreiras }\end{array}$ & $\begin{array}{l}\text { As barreiras à PML foram classificadas em seis } \\
\text { categorias, sendo essas: organizacionais, sistêmicas, } \\
\text { técnicas, econômicas, governamentais e de atitude, } \\
\text { todas apresentadas na tabela } 2 \text {. }\end{array}$ \\
\hline 3 & $\begin{array}{l}\text { Pré-avaliação } \\
\text { diagnóstico }\end{array}$ & $\begin{array}{l}\text { Foram identificadas quais as fontes de informação } \\
\text { existentes na empresa, como banco de dados, } \\
\text { relatórios e documentos. Com o auxílio de planilhas e } \\
\text { fluxogramas foram listados quais dados seriam } \\
\text { necessários para a realização das análises propostas. }\end{array}$ \\
\hline 4 & $\begin{array}{l}\text { Listar entradas e } \\
\text { saídas }\end{array}$ & $\begin{array}{l}\text { Foi realizado o mapeamento de todas as entradas e } \\
\text { saídas do processo produtivo, como matéria prima } \\
\text { (MP), produtos, subprodutos, resíduos e outros } \\
\text { insumos (energia elétrica, produtos auxiliares, água, } \\
\text { etc), com o auxílio do modelo de transformação. }\end{array}$ \\
\hline 5 & $\begin{array}{l}\text { Elaborar } \\
\text { Fluxogramas }\end{array}$ & $\begin{array}{l}\text { O fluxograma foi elaborado com o mapeamento das } \\
\text { entradas e saídas (resíduos sólidos diversos, efluentes } \\
\text { liquidos, emissões atmosféricas, etc.) através do } \\
\text { modelo de transformação. }\end{array}$ \\
\hline 6 & $\begin{array}{l}\text { Coleta e } \\
\text { preenchimento de } \\
\text { dados quantitativos e } \\
\text { qualitativos }\end{array}$ & $\begin{array}{l}\text { A coleta suporta a análise quantitativa e qualitativa } \\
\text { das entradas e saídas do processo escolhido (MP, } \\
\text { insumos, auxiliares, resíduos, efluentes, emissões, } \\
\text { produtos e subprodutos), bem como dados da situação } \\
\text { ambiental da empresa, dados referentes à estocagem, } \\
\text { armazenamento e acondicionamento das entradas e } \\
\text { saídas. } \\
\text { Para a coleta dos dados (geração resíduos, matéria- } \\
\text { prima, produtos e subprodutos, etc.) foram realizadas } \\
\text { reuniões em diferentes setores da empresa. }\end{array}$ \\
\hline
\end{tabular}


Tabela 1 - Continuação...

\begin{tabular}{|c|c|c|}
\hline & Etapa & Aplicação \\
\hline 7 & $\begin{array}{l}\text { Seleção do foco e } \\
\text { Avaliação }\end{array}$ & $\begin{array}{l}\text { Com base nos dados fornecidos foram selecionados os } \\
\text { processos produtivos que seriam o foco do estudo. A } \\
\text { seleção foi orientada pelas razões financeiras, de } \\
\text { legislação, ambiental e de recursos humanos } \\
\text { disponíveis. Também foi levado em consideração } \\
\text { quais processos que a empresa destacou como pontos } \\
\text { críticos. }\end{array}$ \\
\hline 8 & Avaliação das causas & $\begin{array}{l}\text { A partir de uma análise realizada no processo } \\
\text { escolhido foram avaliadas as causas das perdas. } \\
\text { Definiu-se onde, por que e quanto de resíduos e } \\
\text { emissões eram gerados. }\end{array}$ \\
\hline 9 & $\begin{array}{l}\text { Oportunidades de } \\
\text { PML }\end{array}$ & $\begin{array}{l}\text { A última etapa da metodologia proposta constituiu no } \\
\text { levantamento de oportunidades de PML no processo } \\
\text { estudado. As opções foram direcionadas para } \\
\text { classificações pré-estabelecidas que são: Mudança em } \\
\text { matérias-primas, mudança tecnológica, boas práticas } \\
\text { de PML (housekeeping ou "soluções caseiras"), } \\
\text { mudanças no produto, reuso e/ou reciclagem. } \\
\text { Algumas melhorias identificadas podem ser mais } \\
\text { simples e de fácil implementação, outras podem exigir } \\
\text { investimento em novas tecnologias e mudanças } \\
\text { organizacionais complexas. A Tabela } 3 \text { apresenta o } \\
\text { fluxograma qualitativo de todas as correntes de } \\
\text { entrada e saída de cada etapa do processo. }\end{array}$ \\
\hline
\end{tabular}

Tabela 2 - Barreiras identificadas relacionadas à PML.

\begin{tabular}{|l|l|}
\hline \multirow{2}{*}{ Elassificação } & Barreira \\
\hline \multirow{2}{*}{ Econômica } & Falta de investimentos relacionados às questões ambientais. \\
\cline { 2 - 3 } & Falta de incentivos fiscais relativos ao desempenho ambiental. \\
\hline \multirow{2}{*}{ Organizacional } & $\begin{array}{l}\text { Carência ou falha de documentação arquivada. } \\
\text { problemas ambientais. }\end{array}$ \\
\cline { 2 - 3 } & \begin{tabular}{l} 
Foco em medidas corretivas. \\
\hline
\end{tabular} \\
\hline
\end{tabular}

Continua... 
Tabela 2 - Continuação...

\begin{tabular}{|c|c|}
\hline Classificação & Barreira \\
\hline \multirow{4}{*}{ Técnica } & $\begin{array}{l}\text { Falta de recursos necessários à coleta de dados, entradas e saídas do } \\
\text { processo. }\end{array}$ \\
\hline & Concentração de esforços no Controle "Fim-de-tubo". \\
\hline & Limitação ao acesso de informações técnicas. \\
\hline & $\begin{array}{l}\text { Falta de dados quantitativos referentes às entradas e saídas de cada } \\
\text { etapa do processo. }\end{array}$ \\
\hline \multirow{3}{*}{ Governamental } & Falta de estímulo para atuar na minimização da poluição. \\
\hline & Políticas de preços (água e energia). \\
\hline & Carência de regulação ambiental. \\
\hline
\end{tabular}

O processo produtivo de BOPP estudado compreende 9 etapas: Extrusão, MDO, TDO, Pull-Roll, Embobinamento (Winder), Corte, Metalização, Expedição, e a Regranulação. A Tabela 3 apresenta as entradas e saídas referentes ao processo estudado das 9 etapas de acordo com a metodologia de PML e o modelo de transformação.

Alguns resíduos gerados em cada etapa do processo produtivo não foram disponibilizados ou não são quantificados individualmente pela empresa, por isso foram quantificados de forma global.

Com base na análise da quantidade de alguns resíduos gerados, em cada etapa do processo, foi possível identificar os que apresentaram maior volume. As informações referentes a quantidade de SCRAP foram determinadas utilizando uma média, após um período de 4 meses acompanhando a geração deste resíduo, onde foi observado que a geração desse resíduo representa um grande impacto econômico para a empresa. A Tabela 4 agrupa as informações sobre as matérias primas, produtos e subprodutos gerados que foram quantificados durante o estudo.

O SCRAP é denominado como todo material polimérico de saída do processo na forma de resíduo. A maior parte do SCRAP gerado provém de rupturas no filme durante a extrusão, filme fora de especificação, orelas, borra, etc.

A Tabela 5 apresenta informações sobre o processo produtivo do BOPP referentes ao consumo e geração globais, que envolvem uma média de todas as linhas de produção do filme de BOPP dependendo das especificações dos clientes.

Após a realização do mapeamento do processo, com todas as etapas de produção do filme de BOPP, a identificação e quantificação das entradas e saídas, o consumo e geração do processo, a etapa 6 da metodologia foi finalizada.

A etapa 7, que é a definição dos focos de avaliação, foi realizada com base na avaliação dos dados coletados, sendo assim foram definidos os processos onde mais foram identificadas as perdas.

Foram identificadas as fontes e causas dos resíduos e as emissões gerados em maior proporção, bem como as perdas de água e energia. Os dados foram estabelecidos a partir da compreensão de onde, por que e a quantidade de resíduos e emissões gerados e também a quantidade de energia e água dis- 
Tabela 3 - Modelo de transformação para as etapas produtivas do BOPP.

\begin{tabular}{|c|c|c|}
\hline Entradas & $\begin{array}{l}\text { Etapas do processo } \\
\text { produtivo de BOPP }\end{array}$ & Saídas \\
\hline $\begin{array}{l}\text { Homopolímeros } \\
\text { Copolímeros } \\
\text { Aditivos } \\
\text { Energia } \\
\text { Água } \\
\text { Óleos térmicos e } \\
\text { lubrificantes }\end{array}$ & 1- Extrusão & $\begin{array}{l}\text { Filme grosso (cast film) } \\
\text { Óleo descartado } \\
\text { Borra } \\
\text { Energia (calor) } \\
\text { Efluentes líquidos }\end{array}$ \\
\hline $\begin{array}{l}\text { Óleos lubrificantes e } \\
\text { térmicos } \\
\text { Vapor de água } \\
\text { Energia } \\
\text { Placa }\end{array}$ & 2- $\mathrm{MDO}$ & $\begin{array}{l}\text { Filme grosso } \\
\text { Óleo descartado } \\
\text { Efluentes líquidos }\end{array}$ \\
\hline $\begin{array}{l}\text { Filme Grosso } \\
\text { Energia } \\
\text { Óleo }\end{array}$ & 3- TDO & $\begin{array}{l}\text { Filme fino } \\
\text { Gases provenientes da } \\
\text { evaporação dos aditivos } \\
\text { Efluentes líquidos } \\
\text { Emissões Atmosféricas }\end{array}$ \\
\hline $\begin{array}{l}\text { Filme Fino } \\
\text { Energia Életrica } \\
\text { Gás Natural } \\
\text { Água }\end{array}$ & 4- Pull-Roll & $\begin{array}{l}\text { Filme tratado } \\
\text { Ozônio (liberado dependendo do } \\
\text { tratamento superficial) } \\
\text { Orela (margens danificadas pelos } \\
\text { grampos) } \\
\text { Efluentes líquidos }\end{array}$ \\
\hline Filme tratado & $\begin{array}{l}\text { 5- Embobinamento } \\
\text { (Winder) }\end{array}$ & $\begin{array}{l}\text { Mantas de BOPP } \\
\text { Filme no tubo(bobina jumbo) }\end{array}$ \\
\hline
\end{tabular}


Tabela 3 - Continuação...

\begin{tabular}{|c|c|c|}
\hline Filme embobinado & 1- Corte & $\begin{array}{l}\text { Mantas de BOPP } \\
\text { Aparas de BOPP } \\
\text { Fardos de BOPP } \\
\text { Pallets, laterais e ripas de madeira } \\
\text { Tubetes e embalagens de papelão } \\
\text { Pregos e grampos provindos de } \\
\text { pallets } \\
\text { Fita de arquear provinda de pallets } \\
\text { Papel de identificação } \\
\text { Filme de BOPP cortado }\end{array}$ \\
\hline $\begin{array}{l}\text { Fios de Alumínio } \\
\text { Desmoldante } \\
\text { Barcas Cerâmicas } \\
\text { Filme de BOPP cortado } \\
\text { Energia } \\
\text { Pallets, Laterais e ripas } \\
\text { Tubetes e embalagens de } \\
\text { papelão }\end{array}$ & 2- Metalização & $\begin{array}{l}\text { Borra de Alumínio+Desmoldante } \\
\text { de limpeza } \\
\text { Fio de Alumínio } \\
\text { Pallets, Laterais e ripas } \\
\text { Tubetes e embalagens de papelão } \\
\text { Barcas utilizadas } \\
\text { Óxido de Alumínio } \\
\text { Fardo de Material Metalizado } \\
\text { Filme de BOPP Metalizado }\end{array}$ \\
\hline $\begin{array}{l}\text { Filme de BOPP } \\
\text { metalizado ou não } \\
\text { metalizado } \\
\text { Embalagens }\end{array}$ & 3- Expedição & Embalagens danificadas \\
\hline $\begin{array}{l}\text { Filmes fora de } \\
\text { especificação }\end{array}$ & 4- Regranulação & $\begin{array}{l}\text { PP grão } \\
\text { PP pó (material particulado) } \\
\text { Borra }\end{array}$ \\
\hline
\end{tabular}


Tabela 4 - Matéria - prima (MP), Produtos e Subprodutos.

\begin{tabular}{|c|c|c|}
\hline Processo & MP, produtos e subprodutos & Quantidade/ano (t/ano) \\
\hline \multirow{5}{*}{ Extrusão } & Homopolímero & 32.934 \\
\hline & Copolímero & 3.182 \\
\hline & Aditivos & 1.480 \\
\hline & Regranulado & 5.219 \\
\hline & SCRAP & 4.805 \\
\hline \multirow{3}{*}{ Corte } & & 34662 \\
\hline & Metalizado & \\
\hline & SCRAP & 3.516 \\
\hline \multirow{4}{*}{ Metalização } & Borra de Alumínio & 50 \\
\hline & Alumínio & 125 \\
\hline & SCRAP & 157 \\
\hline & $\begin{array}{l}\text { BOPP } \\
\text { Metalizado }\end{array}$ & 12.239 \\
\hline Corte do filme Metalizado & SCRAP & 2.217 \\
\hline
\end{tabular}


Tabela 5 - Consumo/Geração identificados no processo.

\begin{tabular}{|l|l|}
\hline Consumo & Quantidade \\
\hline Água & $13200 \mathrm{~m}^{3} / \mathrm{t}$ produto \\
\hline Energia elétrica & $77.889 .387 \mathrm{KWh} / \mathrm{ano}$ \\
\hline Gás Natural & $1.057 .779,8 \mathrm{~m}^{3} / \mathrm{ano}$ \\
\hline Geração & Quantidade \\
\hline O ${ }_{2}$ (no setor do TDO) & $21 \%$ \\
\hline CO ${ }_{2}$ (no setor de TDO) & $0,05 \%$ \\
\hline Material Particulado (no setor do TDO) & $6 \%$ \\
\hline Sacaria de MP & $11 \mathrm{t} / \mathrm{ano}$ \\
\hline Pallets, laterais e ripas & $5176 \mathrm{t} / \mathrm{ano}$ \\
\hline Tubetes e embalagens de papelão & $126 \mathrm{t} / \mathrm{ano}$ \\
\hline Borra de Alumínio (Al) & 19 carretéis \\
\hline Fio de Al & 46 carretéis \\
\hline Barcas de cerâmica utilizadas & 20.000 a 25000 barcas \\
\hline
\end{tabular}

sipadas e perdidas no processo. Essas análises foram realizadas para serem referenciadas como base para a identificação das oportunidades de PML.

O primeiro processo analisado foi o de Corte, que além dos resíduos poliméricos também foi identificada uma grande quantidade de resíduos não recicláveis na empresa, como madeira e papelão, utilizados nas embalagens e nos pallets. $\mathrm{O}$ custo de adquirir novas embalagens de papelão a cada operação onera a empresa e encarece o processo.

A borra do alumínio gerada durante o processo de Metalização do BOPP também foi identificada como foco de avaliação. Nas câmaras de evaporação o vapor de alumínio gerado adere às paredes da 
máquina, exigindo assim que se realize a limpeza após a metalização de cada bobina. A borra retirada das paredes são vendidas e reutilizadas por outras empresas, a reutilização não acontece na empresa devido a presença do desmoldante, utilizado para realização de limpeza química da máquina metalizadora. que visa facilitar a retirada do alumínio impregnado na máquina. O fio de alumínio que sobra no carretel é enfardado e também é vendido para reciclagem externa (nível 3).

As barcas cerâmicas utilizadas no processo de Metalização também foram identificadas como perdas no processo. Essas barcas têm duração média de 12 a 14 horas, sendo utilizadas cerca de 20.000 a 25.000 unidades por ano. As barcas são compostas de Diboreto de Titânio e Nitreto de Boro, elementos que são importados da Alemanha, USA e Ásia, e são fabricadas através do processo de sinterização, o que confere propriedades como alta resistência a abrasão, a temperatura e passagem de corrente elétrica. Após sua utilização as barcas são descartadas e destinadas à aterros adequados à resíduos industriais.

Foi realizado um acompanhamento das rupturas dos filmes durante o período de quatro meses e, a partir dos dados coletados na empresa foi identificado que a maior parte das rupturas provém de rasgos e furos gerados devido a variações nos parâmetros do processo, como vazão de ar, temperatura e regulagem dos equipamentos. Outras causas que não apresentaram uma frequência no tempo analisado foram os furos, escapes dos grampos que prendem o filme, recorte inapropriado das lâminas e apara enroscada na máquina.

Os pallets e tubetes utilizados pela empresa são de madeira e papelão, respectivamente, e não são reutilizados no processo; sendo, então, revendidos para cooperativas de reciclagem. Estes resíduos são gerados devido a quebra ou fim de vida útil. No caso dos tubetes, que dão suporte interno à bobina de BOPP, seu fim de vida ocorre após o corte da bobina. Já os pallets são descartados quando sofrem danos devido ao peso do material ou manipulação inadequada. $\mathrm{O}$ fim de vida útil é considerado quando não apresenta mais condições de ser reutilizado.

O processo produtivo de fabricação do BOPP consome muita energia e parte dela é dissipada em forma de calor ou então devido a quedas de energia. As quedas de energia são provenientes do fornecedor de energia, no entanto a empresa não possui gerador que evite o desligamento das máquinas durante essas oscilações.

A energia dissipada em forma de calor provém das transformações e processos pelos quais o filme passa, como a extrusão, o MDO e o TDO (estiramento longitudinal e transversal). Este calor é perdido para o meio ambiente, aumentando assim a temperatura do ambiente de trabalho.

O ciclo de utilização de água na empresa é fechado; sendo assim as perdas geradas são provenientes da evaporação nos processos de resfriamento do filme e também perdas em vazamentos de tubulações, válvulas, etc.

\section{I IDENTIFICAÇÃo de Oportunidades de PML no PROCESSO PROdUtivo}

Diante do mapeamento do processo produtivo realizado foram identificadas algumas possibilidades de modificações seguindo as etapas propostas pela metodologia de PML.

As oportunidades estão listadas na Tabela 6 , onde podem ser observadas as gerações de resíduos e emissões, bem como o método de prevenção que pode ser utilizado e, em seguida, a descrição das medidas sugeridas objetivando-se a diminuição ou eliminação da geração de resíduos e emissões.

Grande parte das oportunidades identificadas foram de Nível 1, ou seja, medidas que minimizam a geração de resíduos com redução na fonte. As oportunidades que se enquadraram no Nível 2 focam a reciclagem interna, reutilizando os resíduos gerados dentro do próprio processo. A Tabela 6 foi elaborada com base nas oportunidades identificadas e caracterizadas segundo os níveis propostos pela metodologia de PML.

Algumas oportunidades de aplicação de PML, identificadas no estudo, estão detalhadas a seguir:

- Alguns cuidados podem ser tomados durante a recepção de insumos e matéria-prima, a fim de reduzir o número de resíduos gerados devido a matéria-prima fora de especificação e

inadequação da armazenagem. Uma possível melhoria seria a adoção da prática de recusar embalagens danificadas, não rotuladas ou fora das especificações. Esse controle pode ser realizado durante o recebimento dos insumos e matérias-primas através de inspeção visual durante o descarregamento e armazenagem.

Tal controle pode ser realizado pelos próprios funcionários que realizam o recebimento dos insumos. Os funcionários deste setor seriam treinados para identificarem as inadequações. Pode-se 
utilizar também métodos estatísticos de inspeção da qualidade para selecionar amostras de maneira a não elevar os custos com qualidade (Ramos, 2003).

- Apenas uma pequena parte do regranulado processado é reutilizada no processo. Sua maior parte é revendida por um preço inferior ao que teria se fosse adicionado a produtos de maior valor agregado. Uma alternativa para a diminuição dos resíduos gerados que não são reutilizados no processo é o desenvolvimento de novos produtos cuja matéria-prima principal seja o regranulado ou, então, o aumento da produção de produtos de menores requisitos técnicos que aceitem uma maior porcentagem de regranulado, como alguns tipos de fitas adesivas e filmes para palletização.

Tabela 6 - Oportunidades de PML identificadas no processo.

\begin{tabular}{|c|c|c|}
\hline $\begin{array}{l}\text { Gerações e } \\
\text { emissões }\end{array}$ & Prevenção com: & Descrição da medida \\
\hline \multirow{9}{*}{ SCRAP } & \multirow{5}{*}{$\begin{array}{l}\text { Boas práticas } \\
\text { (housekeeping) - } \\
\text { Nível } 1\end{array}$} & $\begin{array}{l}\text { Alteração na forma de operar os equipamentos- } \\
\text { Procedimentos estabelecidos. }\end{array}$ \\
\hline & & Manutenção preventiva. \\
\hline & & Treinamento da mão de obra. \\
\hline & & $\begin{array}{l}\text { Reorganização do sistema de manutenção } \\
\text { preventiva e corretiva. }\end{array}$ \\
\hline & & Padronização e Normatização. \\
\hline & Reciclagem - Nível 2 & $\begin{array}{c}\text { Parcerias com cooperativas de reciclagem de } \\
\text { plásticos e incentivos a aplicação da metodologia } \\
\text { de PML nos processos de reciclagem das } \\
\text { cooperativas. }\end{array}$ \\
\hline & Reciclagem - Nível 2 & $\begin{array}{l}\text { Downcycling: Utilização do SCRAP para a } \\
\text { fabricação de produtos com: propriedades técnicas } \\
\text { menos rigorosas, por exemplo: fabricação de } \\
\text { outros tipos de filmes ou fitas adesivas. }\end{array}$ \\
\hline & \multirow{2}{*}{$\begin{array}{c}\text { Cuidados na recepção } \\
\text { - Nível } 1\end{array}$} & $\begin{array}{l}\text { Recusar embalagens de matérias-primas, aditivos, } \\
\text { etc, que estejam danificadas, não rotuladas, fora de } \\
\text { especificações. }\end{array}$ \\
\hline & & $\begin{array}{c}\text { Controlar pesos e medidas de todas as etapas do } \\
\text { processo (entradas e saídas). }\end{array}$ \\
\hline
\end{tabular}

Continua... 
Tabela 6 - Continuação...

\begin{tabular}{|c|c|c|}
\hline $\begin{array}{l}\text { Gerações e } \\
\text { emissões }\end{array}$ & Prevenção com: & Descrição da medida \\
\hline SCRAP & $\begin{array}{c}\text { Cuidados na } \\
\text { armazenagem - Nível } \\
1\end{array}$ & $\begin{array}{c}\text { Controlar a qualidade física de tambores, sacos e } \\
\text { outras formas de embalagem, no local de } \\
\text { armazenagem. }\end{array}$ \\
\hline \multirow[t]{2}{*}{$\begin{array}{l}\text { Resíduos de } \\
\text { Pallets e } \\
\text { bobinas }\end{array}$} & $\begin{array}{l}\text { Maximizar utilização } \\
\text { de bobina-Nível } 1\end{array}$ & $\begin{array}{c}\text { Aproveitar ao máximo as bobinas no corte através } \\
\text { de programas computacionais de programação } \\
\text { operacional, que demonstrem a melhor opção de } \\
\text { corte possível. }\end{array}$ \\
\hline & $\begin{array}{l}\text { Substituição de } \\
\text { insumos-Nível } 1\end{array}$ & $\begin{array}{l}\text { Trocar pallets de madeira e bobinas de papelão por } \\
\text { pallets e bobinas de polímero que tenham maior } \\
\text { durabilidade e resistências mecânicas e químicas. }\end{array}$ \\
\hline \multirow{6}{*}{$\begin{array}{l}\text { Dissipação } \\
\text { de Energia } \\
\text { Elétrica }\end{array}$} & $\begin{array}{c}\text { Modificações } \\
\text { tecnológicas - Nível } 1\end{array}$ & Instalação de geradores e nobreaks. \\
\hline & $\begin{array}{c}\text { Modificações } \\
\text { tecnológicas - Nível } 2\end{array}$ & $\begin{array}{l}\text { Reciclagem Energética: através da queima dos } \\
\text { resíduos poliméricos em uma caldeira específica } \\
\text { (SCRAP). }\end{array}$ \\
\hline & $\begin{array}{c}\text { Modificações } \\
\text { tecnológicas - Nível } 1\end{array}$ & $\begin{array}{c}\text { Manutenção, prevenção e ajuste dos } \\
\text { equipamentos. Alguns equipamentos estão } \\
\text { desregulados e não existe a regulagem periódica. }\end{array}$ \\
\hline & $\begin{array}{c}\text { Modificações } \\
\text { tecnológicas - Nível } 1\end{array}$ & $\begin{array}{l}\text { Nos processos de MDO e TDO tentar recuperar o } \\
\text { calor dissipado nesses processos. }\end{array}$ \\
\hline & Medição - Nível 1 & $\begin{array}{l}\text { Instalar medidores de consumo de energia em cada } \\
\text { etapa do processo. }\end{array}$ \\
\hline & $\begin{array}{l}\text { Redução no custo } \\
\text { com energia - Nível } 1\end{array}$ & $\begin{array}{l}\text { Evitar a utilização de algumas máquinas no } \\
\text { período de pico de energia. }\end{array}$ \\
\hline $\begin{array}{l}\text { Perda do } \\
\text { Alumínio }\end{array}$ & Reciclagem - Nível 2 & $\begin{array}{l}\text { Reprocessamento interno da borra de } \mathrm{Al} \text { para } \\
\text { fabricação de novas bobinas de fio de Al. }\end{array}$ \\
\hline
\end{tabular}

Continua... 
Tabela 6 - Continuação...

\begin{tabular}{|c|c|c|}
\hline $\begin{array}{l}\text { Gerações e } \\
\text { emissões }\end{array}$ & Prevenção com: & Descrição da medida \\
\hline \multirow{5}{*}{$\begin{array}{l}\text { Perda de } \\
\text { Água }\end{array}$} & \multirow[t]{2}{*}{$\begin{array}{l}\text { Manipulação de água } \\
\text { - Nível } 1\end{array}$} & $\begin{array}{l}\text { Instalar escorredores para mangueiras, plugues } \\
\text { para vazamentos e redutores de fluxos para } \\
\text { controlar o uso e evitar o excesso de consumo de } \\
\text { água. }\end{array}$ \\
\hline & & $\begin{array}{l}\text { Instalar válvulas de segurança para evitar } \\
\text { vazamento de água nos registros e tubulações. }\end{array}$ \\
\hline & Reciclagem - Nível 2 & $\begin{array}{l}\text { Investigar a possibilidade de retenção } \\
\text { (armazenamento) e reutilização de água de } \\
\text { lavagem e limpeza. }\end{array}$ \\
\hline & \multirow{2}{*}{$\begin{array}{c}\text { Evitar perdas - Nível } \\
2\end{array}$} & Reutilização do vapor perdido durante o processo. \\
\hline & & $\begin{array}{l}\text { Utilizar coberturas nos tanques de resfriamento } \\
\text { para reaproveitar a água condensada. }\end{array}$ \\
\hline \multirow{2}{*}{$\begin{array}{l}\text { Emissões e } \\
\text { Resíduos } \\
\text { (geral) }\end{array}$} & $\begin{array}{l}\text { Monitoramento - } \\
\text { Nível } 1\end{array}$ & $\begin{array}{l}\text { Programa de monitoramento para controlar } \\
\text { emissões e resíduos gerados em cada etapa do } \\
\text { processo de produção. }\end{array}$ \\
\hline & $\begin{array}{l}\text { Modificações de } \\
\text { insumos - Nível } 2\end{array}$ & $\begin{array}{l}\text { Utilizar embalagens que possam ser recicláveis } \\
\text { internamente no processo. }\end{array}$ \\
\hline
\end{tabular}

- Uma parte das perdas geradas no corte provém de sobras de bobinas. As bobinas recebem o corte de acordo com a especificação de dimensão solicitada pelo cliente, relacionada ao tamanho do produto. Uma maneira de se melhor utilizar a bobina durante o corte seria realizar um estudo que forneça os padrões de corte adequados a cada produto através de um modelo computacional simples.

- Atualmente na empresa o controle do consumo energético é realizado com base no consumo da planta inteira, não é especificado o consumo, nem quanto de energia elétrica é dissipada, posteriormente nos processos, em forma de calor, por exemplo. O controle desses parâmetros poderia auxiliar na diminuição do consumo, evidenciando, por exemplo, possíveis erros nos equipamentos ou pontos de perda energética que poderiam ser controlados.

A instalação de medidores de consumo de energia em cada etapa do processo seria uma melhoria simples e eficiente para o controle do consumo de energia. Os medidores auxiliariam no controle de consumo energético, possibilitando a identificação de processos fora de controle, e de pontos de perda de energia. Além disso o ajuste periódico das máquinas (manutenção) evitaria o desperdício devido à máquinas trabalhando de forma inadequada e desregulada.

O consumo energético das linhas de produção do BOPP é alto, sem considerar os desperdícios, o que gera um custo alto para a empresa. Sabe-se que o valor da energia paga durante os horários de pico é maior. Muitas quedas de energia ocorrem durante esse período, gerando uma necessidade de 
reinicialização das máquinas, aumentando ainda mais a geração de resíduos poliméricos devido as paradas dos equipamentos e o custo do processo.

A instalação de geradores ou estabilizadores seria um investimento que traria retornos financeiros para a empresa a médio prazo, o custo do investimento seria coberto pela minimização do gasto energético com reinicialização da máquina, além de ganhos na produtividade e redução dos resíduos gerados.

Outro investimento seria o uso da reciclagem energética, que poderia ser realizado pela queima dos resíduos poliméricos em uma caldeira específica. O poder calorífico dos polímeros é alto e muito maior que de outros materiais. O poder calórifico de $1 \mathrm{~kg}$ de resíduo polimérico é comparável ao de $1 \mathrm{~L}$ de óleo combustível e maior do que o do carvão (Spinacé, 2004). Neste caso o investimento necessário seria alto e deve-se realizar uma análise de viabilidade técnica e econômica.

A cogeração de vapor e eletricidade é também uma alternativa para a diminuição do consumo energético. A cogeração é basicamente o emprego de mais de um ciclo termodinâmico num processo de produção de energia elétrica com o objetivo de aumentar a eficiência do processo. Ela se utiliza da combinação de calor e eletricidade proveniente do combustível utilizado no processo de geração de energia. No caso da utilização do gás natural uma boa solução para a cogeração é a utilização de uma turbina a gás. Nesta solução a relação vapor-eletricidade pode se adaptar com maior flexibilidade às necessidades normais da indústria. A vantagem deste método é a produção de uma energia confiável (sem oscilações de queda), com baixo custo, tornando a empresa independente do fornecimento do distribuidor de energia local.

- Os resíduos não recicláveis internamente e utilizados no processo, como, por exemplo, a madeira e o papelão, poderiam ser substituídas por embalagens plásticas, que são mais flexíveis e resistentes. Os pallets também poderiam ser substituídos por pallets de materiais plásticos, de maneira a facilitar o transporte, garantindo maior durabilidade a embalagem.

- Grande parte do alumínio que entra no processo é eliminado em forma de borra, uma vez que apenas uma pequena parcela adere ao filme metalizado. A empresa poderia realizar um estudo sobre formas de se reutilizar a borra de alumínio, tanto em outros processos como para a fabricação de novas bobinas. A alternativa demandaria um investimento financeiro na compra de equipamentos que realizem essa reciclagem, sendo assim um estudo de viabilidade econômica deveria ser realizado.

- A matéria-prima utilizada atualmente no processo é o polipropileno proveniente do petróleo, uma alternativa proposta seria a utilização do polipropileno "verde" proveniente do etanol da cana de açúcar. Um estudo preliminar de ecoeficiência do biopolímero, realizado em parceria com a Fundação Espaço Eco e utilizando como base os dados da engenharia conceitual, revelou que para cada tonelada de polipropileno "verde" produzida, aproximadamente 2,3 toneladas de $\mathrm{CO}_{2}$ devem ser capturadas da atmosfera e fixadas (Braskem, 2014). A esse ganho ambiental soma-se o fato da resina "verde" ter as mesmas propriedades técnicas e desempenho do polipropileno produzido a partir das rotas tradicionais.

- Determinação e acompanhamento dos indicadores propostos na metodologia de PML: consumo de água $\left(\mathrm{m}^{3}\right) / \mathrm{kg}$ produto produzido; consumo de energia $(\mathrm{kW}) / \mathrm{kg}$ produto produzido; matéria-prima $/ \mathrm{kg}$ produto produzido; resíduo sólido gerado $(\mathrm{kg}) / \mathrm{kg}$ produto produzido; resíduo sólido perigoso gerado $(\mathrm{kg}) / \mathrm{kg}$ produto produzido; efluente líquido gerado $\left(\mathrm{m}^{3}\right) / \mathrm{kg}$ produto produzido; custos de disposição de resíduos ( $\mathrm{R} \$ / \mathrm{kg}$ resíduo); custos de tratamento de efluentes ( $\mathrm{R} \$ / \mathrm{m} 3$ efluente).

\section{CONCLUSÃO}

A PML, por ser uma metodologia de aplicação contínua devido ao monitoramento e por mobilizar toda a organização, necessita de uma mudança na cultura da organização onde será implantada. Isto afeta diretamente todos os níveis organizacionais dentro da empresa, exigindo uma mudança na concepção de produção. Da mesma forma, por ser uma metodologia participativa, pode contribuir para agregar valor à cultura organizacional, envolvendo e motivando as pessoas para atuarem com responsabilidade socioambiental nas empresas. Durante a apresentação da metodologia a principal questão discutida foi a dificuldade para definir a equipe de trabalho devido a grande concentração de esforços dada no momento para produção.

As principais barreiras identificadas foram a concentração dos esforços em controles "fim de tubo"(medidas corretivas), limitação a informações técnicas de processo, falta de estímulo para atuar na 
minimização da poluição, carência de regulamentação ambiental (vários projetos estão sendo inicializados com esse foco), falta de incentivos fiscais relativos ao desempenho ambiental e de investimentos realacionados a questões ambientais, excessivo foco na produção (demanda dos clientes) comparado a minimização dos problemas ambientais, etc.

As visitas técnicas comprovaram que a empresa necessita de quantificar os inputs e outputs em cada etapa da produção, pois os dados gerais não auxiliam na busca do foco específico de consumo de recursos, geração de resíduos, emissões, etc. Com a quantificação dos inputs e outputs seria possível determinar os indicadores sugeridos na implementação de PML citados no trabalho.

As oportunidades identificadas com o auxílio do mapeamento podem trazer benefícios ambientais para a empresa mas tem-se a necessidade de investimentos financeiros, sendo necessário um estudo de viabilidade econômica de todas as oportunidades levandadas no estudo, o que não foi executado neste estudo e que pode ser considerado em um estudo futuro.

Essas oportunidades de melhoria poderão ser implementadas pela empresa após um estudo da viabilidade econômica, de maneira contínua e gradual, conforme sua disponibilidade econômica visando uma maior eficiência no processo produtivo com o objetivo de reduzir o impacto ambiental.

Assim, para as empresas que competem em um mercado cada vez mais exigente na busca pelo desenvolvimento sustentável, a PML pode ser considerada como um impulso para a obtenção de vantagens competitivas frente aos concorrentes e a análise dos processos no contexto da PML pode contribuir com o processo de tomada de decisão em relação a futuros investimentos econômicos nos processos produtivos.

\section{REFERÊNCIAS}

BRASKEM - POLIPROPILENO VERDE (PP VERDE). Disponível em: < http://www.braskem.com.br/site. aspx/Polipropileno-Verde-PP-Verde>. Acesso em 17 de Abr. de 2014;

CARVALHO, L. B. Produção de Polipropileno Bi-Orientado (BOPP): Tecnologias e Aplicações. Bragança, PA 2008.

CEBDS - Conselho Empresarial Brasileiro para o Desenvolvimento Sustentável. Visão Brasil 2050, 2012.

CETESB. Implementação de um Programa de Prevenção à Poluição. São Paulo, SP: Cartilha, 2002.

CNTL, CENTRO NACIONAL TECNOLOGIAS LIMPAS. Implementação de Programas de Produção mais Limpa, 2003.

CORAL, E. Modelo de planejamento estratégico para a sustentabilidade empresarial. Tese Doutorado em Engenharia de Produção, 2002.

CORREIA, B.R.B. e JERÔNIMO, C.E.M., Oportunidades de Produção Mais Limpa no consumo de recursos hídricos na exploração \& produção de petróleo on shore no estado do RN, Rev. Elet. em Gestão, Educação e Tecnologia Ambiental, v(7), nº 7, p. 1335-1348, , 2012.

FARIA, F. P. E PACHECO, E.B.A.V., A reciclagem de plástico a partir de conceitos de Produção Mais Limpa, GEPROS. Gestão da Produção, Operações e Sistemas - Ano 6, nº 3, p. 93-107, 2011.

FRESNER, J. Small and medium sized enterprises and experiences with environmental management., Journal of Cleaner Production, v. 12, p. 545-547, 2004.

HATCHER, G. D.; IJOMAH, W. L.; WINDMILL, J. F. C.; Design for remanufacture: a literature review and future research needs. Journal of Cleaner Production, v. 19, p. 2004-2014, 2011.

HINZ, R. T. Sustentabilidade ambiental das organizações através da produção mais limpa ou pela avaliação do ciclo de vida. Estudos Tecnológicos Vol.2, 91-98, 2006. 
LECETA, I.; GUERRERO, P.; CABEZUDO, S.; KABA, K.; Environmental assessment of chitosan-based film. Editora Elselvier, Journal of Cleaner Production, 2013 - Vol. 41, 312 - 318 pp.

LOPES SILVA, D.A., et al., Quality tools applied to Cleaner Production programs: a first approach toward a new methodology, Journal of Cleaner Production (2012)

MIGUEL, P.A.C., Desdobramento da Qualidade no Desenvolvimento de Filmes Flexíveis para Embalagens, Polímeros: Ciência e Tecnologia, vol. 13, nº 2, p. 87-94, 2003.

MMA. Ministério do Meio Ambiente: Supermercados "verdes". Disponível em: http://www.mma.gov.br. Acesso em 9 set. 2013.

RAMOS, A. S. M.; MIRANDA, A. L. B. Processos de adoção de um sistema integrado de gestão: uma pesquisa qualitativa com gestores da Unimed/Natal.Porto Alegre: Encontro Nacional De Engenharia De Produção, 2003.

SEBRAE. A produção mais limpa na micro e pequena empresa. Centro Nacional de Tecnologias Limpas SENAI,2005.

SIDERURGIA BRASIL. Embalagens metalizadas de BOPP são recicláveis. Revista Siderurgia Brasil, São Paulo, ed. 66, 2010.

SILVA FILHO, J.C.G. e SICSÚ, A. B.,Produção Mais Limpa: uma ferramenta da Gestão Ambiental aplicada às empresas nacionais", XXIII Encontro Nac. de Eng. de Produção - Ouro Preto, MG, Brasil, 21 a 24 de out de 2003.

SLACK, N. ; CHAMBERS, S.; JOHNSTON, R. Administração da Produção. São Paulo, Atlas. 2009.

SPINACÉ, M. A. ATecnologia de Reciclagem de Polímeros.Quim. Nova, 2004 p. 65-72.

TAMURA, S.; OHTA, K.; KANAI, T. Study of crater structure formation on the surface of biaxially oriented polypropylene film. Journal of Applied Polymer Science, [s. 1.], v. 124, n. 4, p. 2725-2735, 2012.

VOSS, C.; TSIKRIKTSIS, N.; FROHLICH, M. Case Research in Operations Management. International Journal of Operations \& Production Management, v. 22 n. 2, p. 195-219, 2002.

WILLIAMS, H.; WIKSTRÖM; F.; Environmental impact of packaging and food losses in a life cycle perspective: a comparative analysis of five food items. Editora Elselvier, Journal of Cleaner Production,Vol. 19, 43 -48 pp, 2011.

ZAMPOLLO, D. M. e NEDER, L. T. C. Iniciativas de Produção Mais Limpa na Indústria de Petróleo e Gás, In 4th. International Workshop International Workshop -Advances in Advances in Cleaner Production, "INTEGRATING CLEANER PRODUCTION INTO SUSTAINABILITY STRATEGIES", São Paulo - Brazil - May 22nd to 24th - 2013 